\title{
Mechanical complications in adult spinal deformity and the effect of restoring the spinal shapes according to the Roussouly classification: a multicentric study
}

\author{
Amer Sebaaly ${ }^{1,2,3} \cdot$ Martin Gehrchen $^{4} \cdot$ Clément Silvestre $^{1} \cdot$ Khalil Kharrat $^{2,3} \cdot$ Tanvir Johanning Bari $^{4}$. \\ Gabi Kreichati $^{2,3} \cdot$ Maroun Rizkallah $^{2,3}$. Pierre Roussouly ${ }^{1}$
}

Received: 15 August 2019 / Revised: 28 October 2019 / Accepted: 19 November 2019 / Published online: 26 December 2019

(c) The Author(s) 2019

\begin{abstract}
Purpose To evaluate the incidence of mechanical complications in patients with adult spine deformity (ASD) treated by restoring the normal shape according to the Roussouly classification.

Methods This is a retrospective multicentric study with a minimum follow-up of 2 years. Patients operated on with fusion for ASD (minimum performed fusion: L2 to sacrum) were included. Patients with a history of previous spinal fusion of more than three levels were excluded. Spinal and pelvic parameters were measured on the preoperative and the immediate postoperative follow-up. All mechanical complications were recorded.

Results A total of 290 patients met the criteria of inclusion with a minimum follow-up of 2 years. Mechanical complications occurred in $30.4 \%$ of the cohort. The most common complication was PJK with an incidence of $18 \%$ while nonunion or instrumentation failure (rod breakage, implant failure) occurred in $12.4 \% .66 \%$ of the patients were restored to the normal shape according to the Roussouly classification based on their PI and had a mechanical complication rate of $22.5 \%$, whereas the remaining $34 \%$ of patients had a complication rate of $46.8 \%(p<0.001)$. The relative risk for developing a mechanical complication if the algorithm was not met was 3 (CI $1.5-4.3 ; p<0.001$ )

Conclusion In the recent literature, there are no clear guidelines for ASD correction. Restoring the sagittal spinal contour to the normal shapes of Roussouly according to the PI could serve as a guideline for ASD treatment. Ignoring this algorithm has a threefold risk of increased mechanical complications. We recommend this algorithm for treatment of ASD.

Level of evidence IV cross-sectional observational study.
\end{abstract}

\section{Graphic abstract}

These slides can be retrieved under Electronic Supplementary Material.
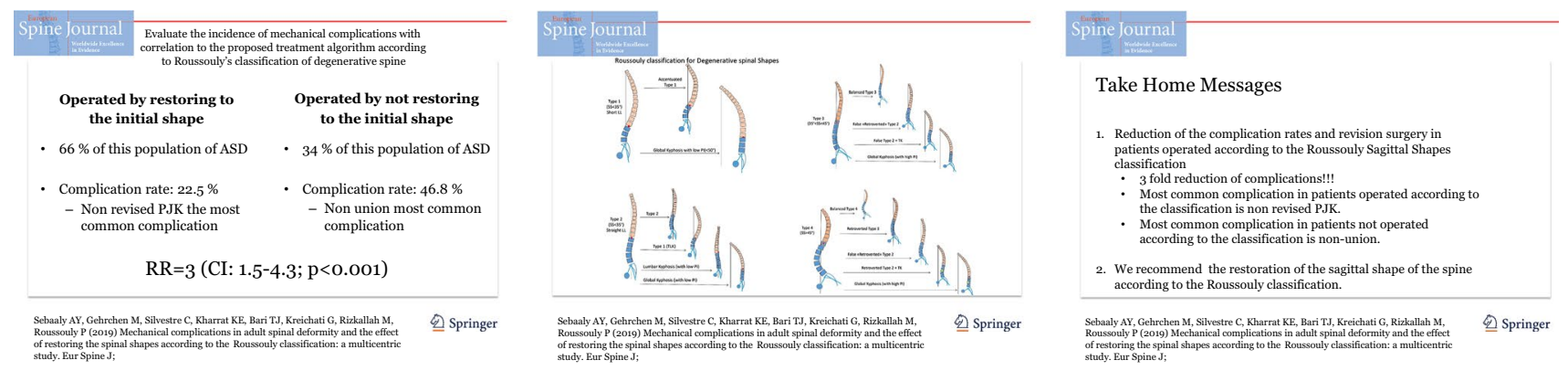

Keywords Degenerative spine $\cdot$ Adult spinal deformity $\cdot$ Scoliosis $\cdot$ Complications $\cdot$ Roussouly classification

Electronic supplementary material The online version of this article (https://doi.org/10.1007/s00586-019-06253-1) contains supplementary material, which is available to authorized users.

Extended author information available on the last page of the article 


\section{Introduction}

The incidence of adult spinal deformity (ASD) in general and adult scoliosis in particular is increasing with the age of the population. It ranges between $29 \%$ at the age of 54 years to more than $65 \%$ after the age of 65 years [1]. It is associated with poor quality of life, especially when coronal and sagittal imbalance are present [2]. Surgical treatment of adult scoliosis is challenging and requires complex surgical techniques in patients with multiple comorbidities. It is associated with a high revision rate (50\% at 10 years) and an increased mortality $[3,4]$.

ASD surgery is associated with a $20-50 \%$ incidence of mechanical complications [pseudarthrosis, proximal junctional kyphosis (PJK)...] [4]. PJK was first described in Scheuermann's kyphosis [5] and adolescent idiopathic scoliosis [6]. The functional consequences can often lead to multiple surgical revisions [7]. On the other hand, distal fixation in long posterior spinal fixation is crucial since, even with the advancement of spinal instrumentation, there is up to $44 \%$ incidence of distal mechanical complications in ASD surgery [8].

Roussouly presented in 2005 his classification of the spinal shapes in the normal population [9]. Prior to this study, no classification was done to describe the normal shapes of the asymptomatic spine. Four types of spinal shapes were described depending on the SS and the shape of the lumbar lordosis. This classification has been recently updated to include a fifth type, the anteverted type 3 (Fig. 1) [10]. Moreover, a new classification describing the evolution of the asymptomatic typology under degenerative conditions has been recently proposed by Roussouly [11] (Fig. 2).
In the recent available medical literature, there are no clear guidelines for ASD correction as PI-LL formula yielded unacceptably high rates of mechanical complications and the updated age specific goals are yet to yield definitive guidelines [12]. Moreover, it has recently been published that restoring the apex of the lordosis to the levels corresponding to the Roussouly classification would reduce the risk of PJK by a ratio of 4.6 [13]. Based on the fact that identification of the correspondence between pelvic incidence and spinal degenerative shape would allow recognizing the original "normal" shape, the proposed algorithm is to restore the low-pelvic-incidence patients to type 1 or type 2 while restoring higher-pelvic-incidence patients to type 3 and type 4 . The main objective of this multicentric study was to evaluate the incidence of mechanical complications in surgical treatment of ASD with correlation to the spinal shapes.

\section{Methods}

This is a retrospective multicentric radiological study. The inclusion period started in January 2010 and ended in December 2016, aiming to have a minimum follow-up of 2 years. Patients aged $\geq 18$ years and operated on with lumbar fusion for degenerative spine disease with a fusion from L2 to the sacrum (or longer, with or without pelvic fixation-minimum 4 fused levels including the sacrum) were included in this study. Long standing X-ray (digital or EOS ${ }^{\circledR}$ ) of the full spine preoperatively, in the immediate postoperative period and at the last follow-up, had to be available for inclusion. Exclusion criteria were: (1) history of previous spinal fusion of more than three levels (four included vertebras), (2) scoliosis secondary to a tumoral etiology, (3) scoliosis with neuro-muscular etiology (Parkinson's, etc.)
Fig. 1 Classification of the normal sagittal alignment according to Roussouly into five types according to the PI. (Modified from [10] Classification of normal sagittal spine alignment: refounding the Roussouly classification. Eur Spine J. https://doi.org/10.1007/s0058 6-017-5111)

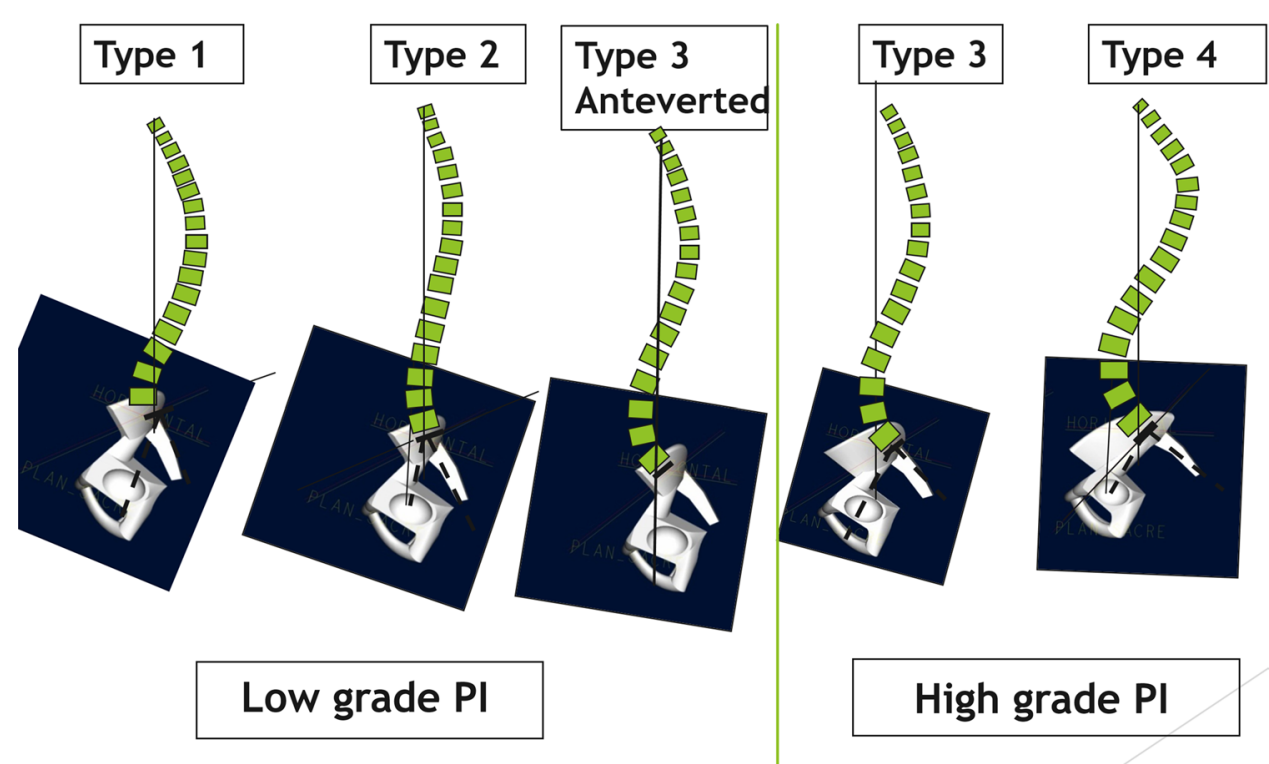



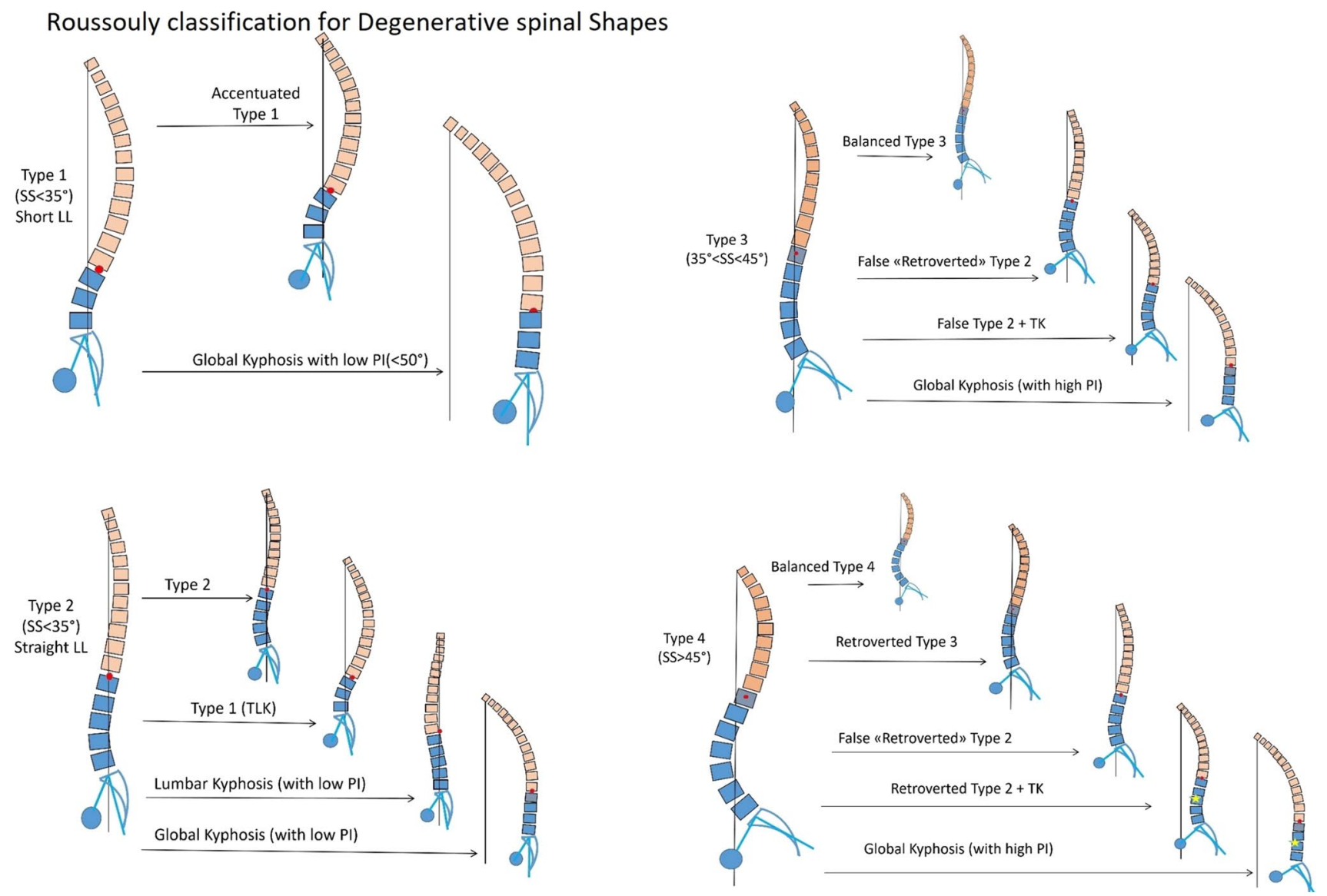

Fig. 2 Classification of the degenerative spinal sagittal alignment according to Roussouly into 11 types according to the initial shape. (Modified from [11] Description of the sagittal alignment of the degenerative human spine. Eur Spine J. https://doi.org/10.1007/s00586-017-5404-0)

and (4) records with missing data. Laminectomy, discectomy and fusion of two levels were not considered as exclusion criteria.

A spine surgeon (AS) and spine fellow (MR), who were not involved in the surgical treatment of the patients, collected and measured retrospectively all radiographic data. Full spine radiographs were analyzed using semi-manual computerized software for sagittal spinopelvic and scoliosis curvature radiologic measurements, KEOPS ${ }^{\circledR}$ (SMAIO, Lyon, France) which has shown excellent reliability in measuring sagittal and coronal parameters [14]. The radiographic measures that were made are the following:

- Pelvic incidence (PI) angle formed by the line drawn from midpoint of the upper sacral endplate to the center of hip axis (HA) and the line perpendicular to the upper sacral endplate.

- Pelvic tilt $(P T)$ angle between the line through the midpoint of the sacral endplate to femoral heads axis and the vertical axis.

- Sacral slope (SS) angle between the upper sacral endplate and the horizontal line
- Spinal lordosis (SL) Cobb angle between the superior endplate of S1 and the upper endplate of the vertebra at the inflexion point. It is different from the lumbar lordosis LL (L1-S1 lordosis)

- Spinal kyphosis (SK) Cobb angle between the thoracolumbar inflexion point and the cervicothoracic inflexion point.

- Number of vertebrae in SL (NVL)

- Barrey ratio The ratio between the SVA and the distance between the posterior corner of the sacral endplate and the vertical line passing by the hip axis [15].

Proximal junctional kyphosis was defined according to the definition of Glattes: PJK angle is determined by the angle between the lower endplate of the upper instrumented vertebra and the upper endplate of the second supra-adjacent vertebrae. Proximal junctional kyphosis is considered present when the PJK angle is superior to $10^{\circ}$ and is at least $10^{\circ}$ greater compared its preoperative value [16]. Nonunion was defined if there was a fracture of the rods, loosening of the instrumentation or clear nonunion on the CT scanner (if performed). PJK and nonunion were chosen to be analyzed 
because when a construct fails, it could fail inside (nonunion) or above it (PJK). Patients were then divided into two groups: in the first group, the operative strategy matches the proposed algorithm (low-PI group $\left(<50^{\circ}\right)$ restored to types 1 and 2 and high-PI $\left(\geq 50^{\circ}\right)$ group restored to types 3 and 4$)$. In the second group, the operative strategy does not match the proposed algorithm. Complications and all measured variables were compared between both groups.

SPSS 18.0 (International Business Machines Corporation, Armonk NY) was used for statistical analysis. Shapiro normality test was used to test the normal distribution of the cohort. Fisher exact test was used for continuous variables, and a Chi-squared $\chi^{2}$ test was performed for non-continuous variables. Hazard ratios (HR) for predictive factors will be then calculated. $p$ value of 0.05 will be the threshold for statistical significance.

\section{Results}

Two hundred ninety (290) patients met the inclusion criteria with a minimum follow-up of 2 years. The mean age was 58.4 years (19-79 years), and the mean follow-up in this series was 66 months (24-91) with female-to-male ratio of 3.6/1. Mean BMI was 25.4 (17.2-38.4).

Analysis of the spinal parameters is shown in Table 1. The mean pelvic incidence was $52.6^{\circ}\left(25^{\circ}-89.3^{\circ}\right)$. Mechanical complications occurred in $30.4 \%$ of the cohort. The most common complication was PJK with an incidence of $18 \%$, while nonunion or instrumentation failure (rod breakage, implant failure) occurred in $12.4 \%$.

Sixty-six percent of the patients were operated according to the proposed algorithm (Fig. 3) and had a mechanical complication rate of $22.5 \%$, whereas the remaining $34 \%$ of patients (Fig. 4) had a complication rate of $46.8 \%$ $(p<0.001)$. When comparing the patients in whom the algorithm was abided and the patients in whom it was not, only preoperative $\mathrm{PT}$ was higher in the latter $\left(21.9^{\circ}\right.$ vs $\left.26.7^{\circ}, p<0.001\right)$. Finally, the relative risk for developing a
Fig. 3 64-year-old female presented with a postsurgical flat back. Spinal parameters analysis showed a global kyphosis type with small PI (42) (a). Simulation of the osteotomy was done to do a L4 pedicle substraction osteotomy with a restoration of a type 2 since the patient had a flat thoracic kyphosis (b). 2-year follow-up with good sagittal alignment and no mechanical complications (c)

mechanical complication if the algorithm was not met was 3 (CI 1.5-4.3; $p<0.001$ ).

When comparing patients who developed complications with those who did not (Table 2), patients who developed complications had a trend, although not significant, toward a higher age (57.3 yrs vs 60.3 years, $p=0.06$ ) and had a significant higher PT, pre-op, post-op and at the last follow-up measurements (respectively, $22.1^{\circ}$ vs $26.2^{\circ}, p=0.03 ; 19.7^{\circ}$ vs $22.4^{\circ} ; p=0.01 ; 20.4^{\circ}$ vs $24.3^{\circ}, p=0.02$ ). There was also a higher postoperative Barrey ratio in patients with complications $(80 \%$ vs $120 \%, p=0.01)$.

When comparing the patients with high PI and low PI, there was a trend to a higher complication rate in the highPI group (35.8\% vs $26.1 \%$, respectively; $p=0.07$ ). It was noticed that $77 \%$ of the patients with low-PI group were given type 1 and type 2 shapes postoperatively, whereas only $58 \%$ of the patients with high PI had type 3 or type 4 shapes postoperatively. The highest rate of complications was found in the cases where the postoperative shape was the false type 2 shape $(52.6 \%)$ followed by false type $3(36.3 \%)$, whereas normal Roussouly types (types 1 to 4 ) had similar (and lowest) complication rates around $18 \%$.

\section{Discussion}

Sagittal balance understanding is a primordial factor in implementing an accurate surgical strategy in degenerative spine. Recently, Sebaaly et al. [11] have described the Roussouly classification for degenerative spinal diseases. But, many criticized Roussouly classifications for being described in normal population and unusable in degenerative
Table 1 Descriptive statistics of pelvic and spinal parameters of this study's cohort

\begin{tabular}{lcllllll}
\hline & \multicolumn{3}{c}{ Preoperative measure } & & & \multicolumn{2}{c}{ Postoperative measure } \\
\cline { 2 - 3 } & Mean & Minimum & Maximum nn & & Mean & Minimum & Maximum \\
\hline Pelvic incidence & 52.6 & 25 & 89.3 & & & \\
Pelvic tilt & 23.7 & -6.5 & 54.0 & & 21.2 & -5.0 & 52.3 \\
Sacral slope & 29.2 & -28.0 & 60.7 & & 31.5 & -10.0 & 58.7 \\
Spinal lordosis (SL) & 45.4 & -7 & 103 & & 50.3 & 10.0 & 92.0 \\
Number of vertebra in SL & 5.9 & 2 & 13.0 & & 7 & 4 & 10 \\
Spinal kyphosis (SK) & -50.4 & -114.0 & -3.9 & & -50.7 & -107.7 & 1.6 \\
Number of vertebra in SK & 11.8 & 2 & 17 & & 10 & 4 & 15 \\
Barrey ratio & $86.5 \%$ & $-90 \%$ & $560 \%$ & & $92.1 \%$ & $-428 \%$ & $931 \%$ \\
Global tilt & 64.3 & 30.2 & 124.8 & & 59.5 & 16.3 & 105.0 \\
\hline
\end{tabular}


A

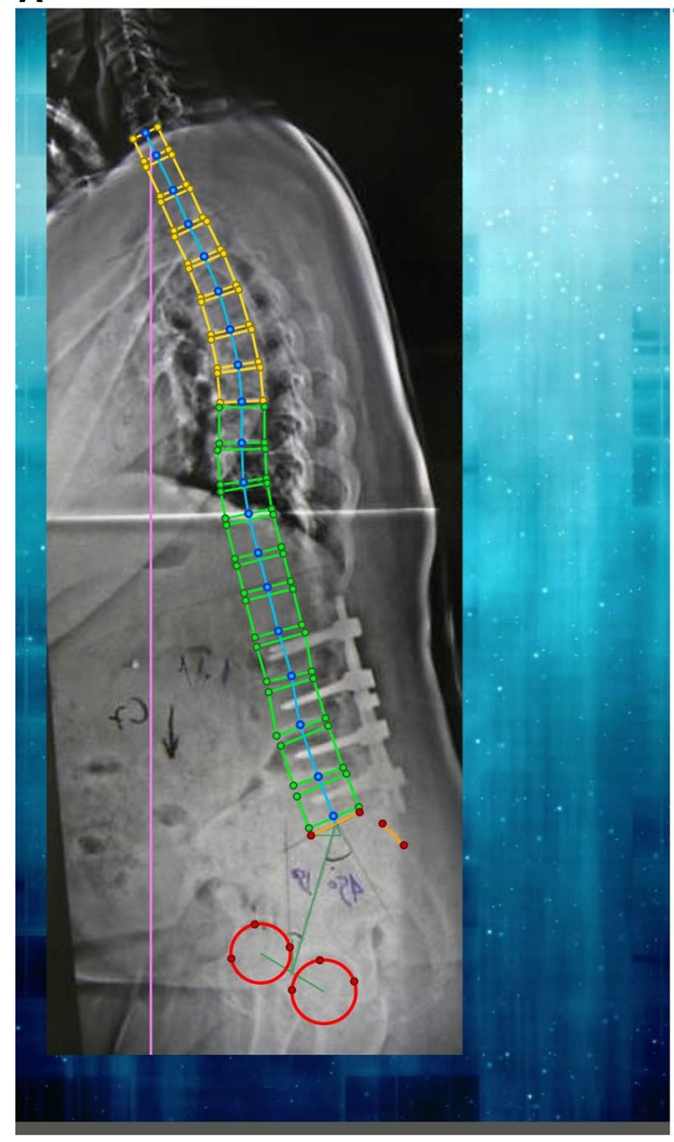

PELVIS

ncidence pelvienne

Version pelvienne

Pente Sacrée

BALANGE

Ratio de Barrey

SVA

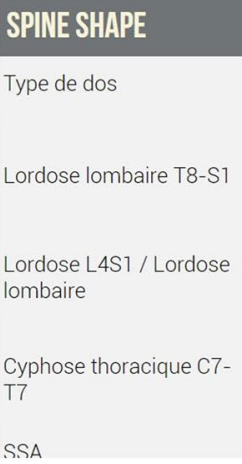

B
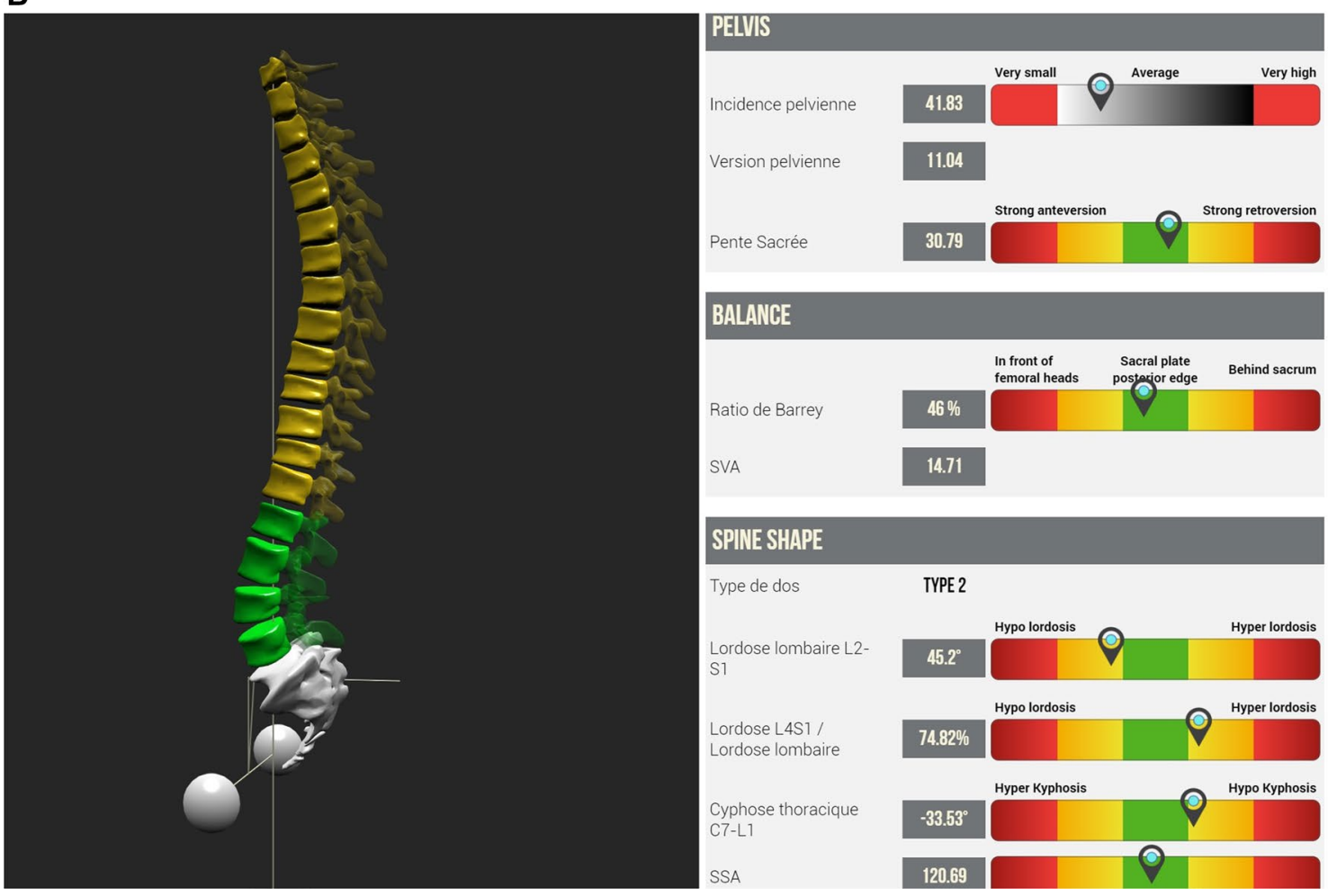

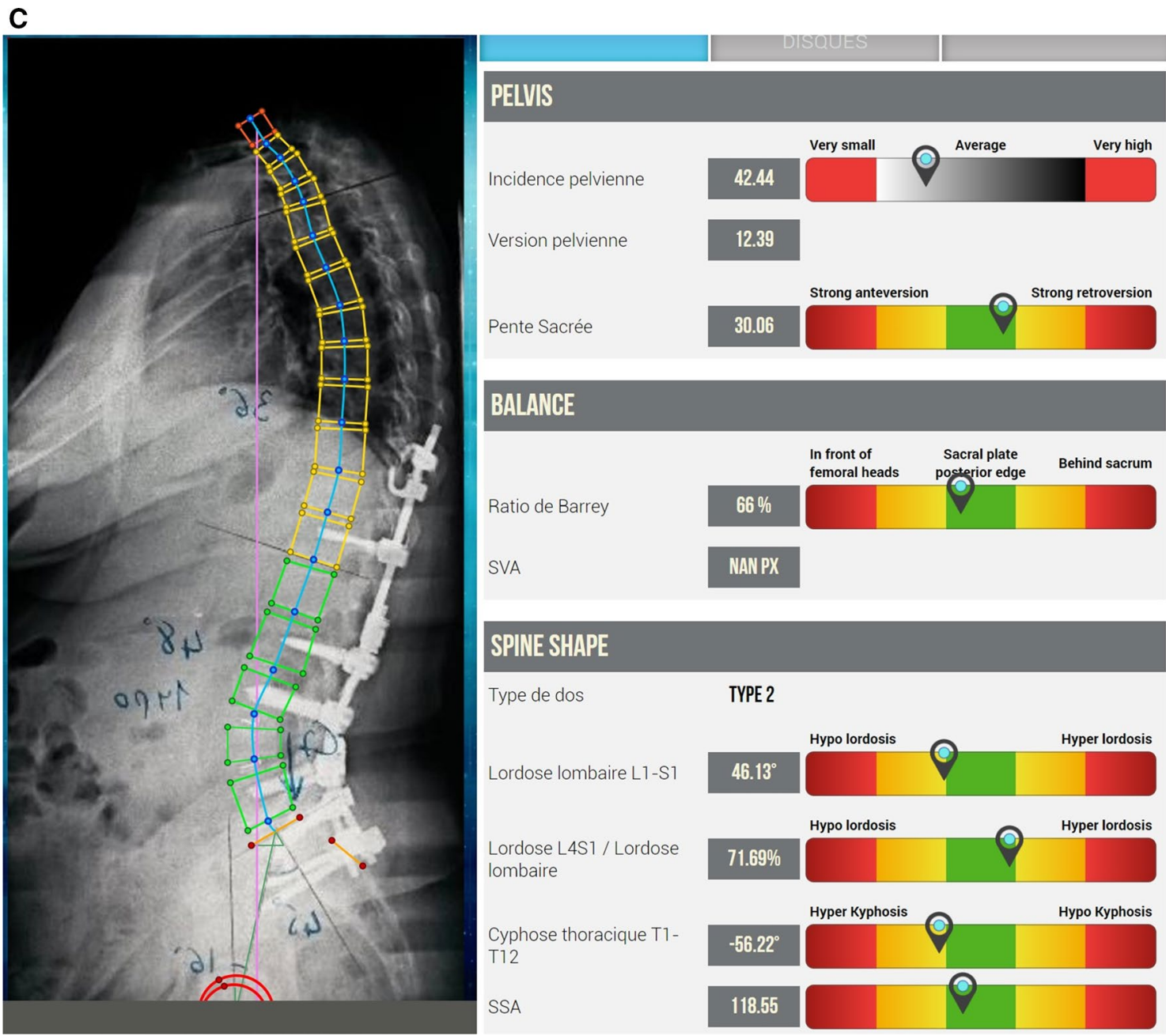

Fig. 3 (continued)

disease, while others stated that it cannot be widely applied and that it will be poorly understood in the physician population. We have found that restoring the shape according to PI decreases by threefold the rate of mechanical complications.

PJK is a common complication of corrective surgery for ASD with an incidence ranging between 6 and 50\% [8,9]. We have found an incidence of $18.4 \%$ of PJK in this population similar to that reported in the literature [17]. In a recent evaluation of a large database of adult deformity patients, restoring the sagittal apex of the lordosis and its effects on the incidence of PJK was analyzed [13]. When postoperative sagittal apex of the lumbar curve was identical to the theoretical apex, PJK occurred in $13.5 \%$ of the cases, whereas it occurred in $41.4 \%$ in cases where the theoretical and actual apex were different $(p=0.01)$ with an $\mathrm{OR}=4$.6. The restoration of the sagittal apex of the lordosis is no other than the restoration of the initial shape according the PI.

The main finding of this study emphasizes the importance of the sagittal shape of the spine. The spine should be harmonious with an angle distribution as described
Fig. 4 61-year-old female presented with sagittal and coronal imbalance $(\mathbf{a}, \mathbf{b})$. Spinal parameters analysis showed a high pelvic incidence (60) with low lumbar lordosis with an overall false type 2 shape (a). She was operated by using Ponte osteotomies with small correction of the sagittal balance keeping her shape as a false type 2 (c). She presented a symptomatic PJK 6 months postoperatively with T12 fracture (d)

by Berthonnaud et al. [18]. Limited angles and simplified formulas should be replaced by a vision of the whole spine. Surgeons must avoid using correction techniques to the whole spine according to a simple formula involving a fixed angle and the LL or a more complex formula involving some part of the lumbar lordosis (L4-S1). LL in its anatomical landmarks (L1S1) characterized by one angle has brought to a simple formula (PI-LL) excluding variable length and inside curvatures repartition. In Berthonnaud's model, lordosis length is variable and may be shorter or longer than LL In opposition to the anatomical LL, we used here the functional spinal lordosis (SL). SL 


\section{A}

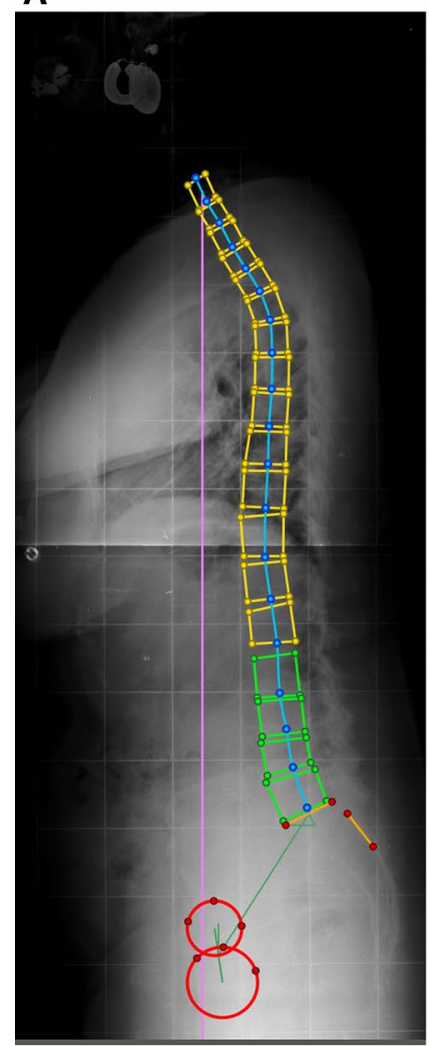

C

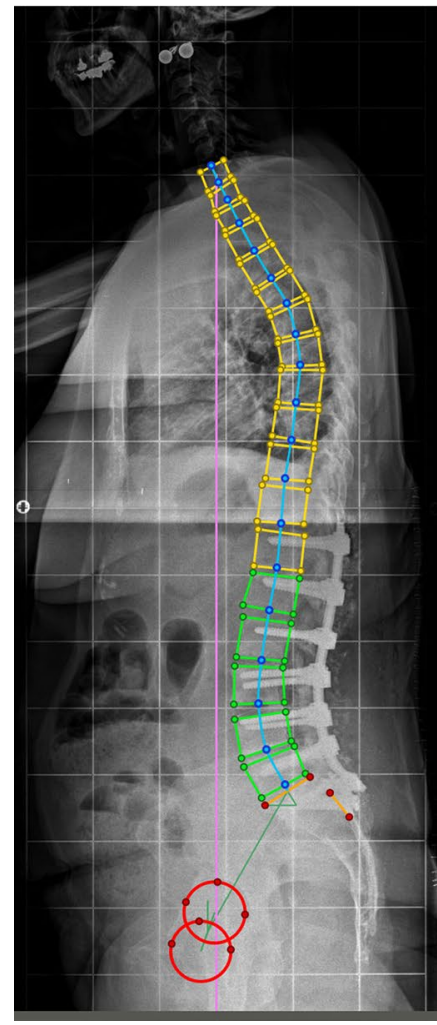

Pelvic Incidence

Pelvic Tilt

Sacral Slope

\section{BALANGE}

\begin{tabular}{l|l|l|}
\hline Barrey ratio & $114 \%$ \\
SVA & $101.43 \mathrm{PX}$
\end{tabular}

\section{SPINE SHAPE}

Back type

Lumbar lordosis L2-S1

Lordose L4S1 / Lumbar

Lordose
lordosis

Thoracic kyphosis C7-

L1

SSA

SSA

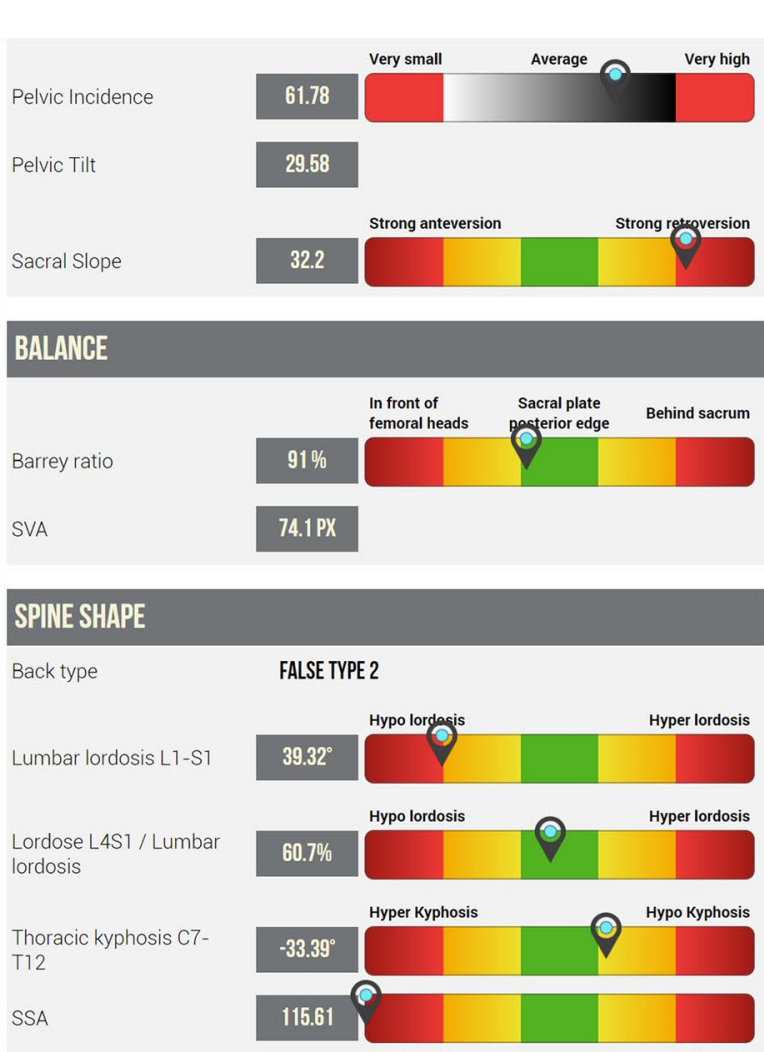

\section{B}
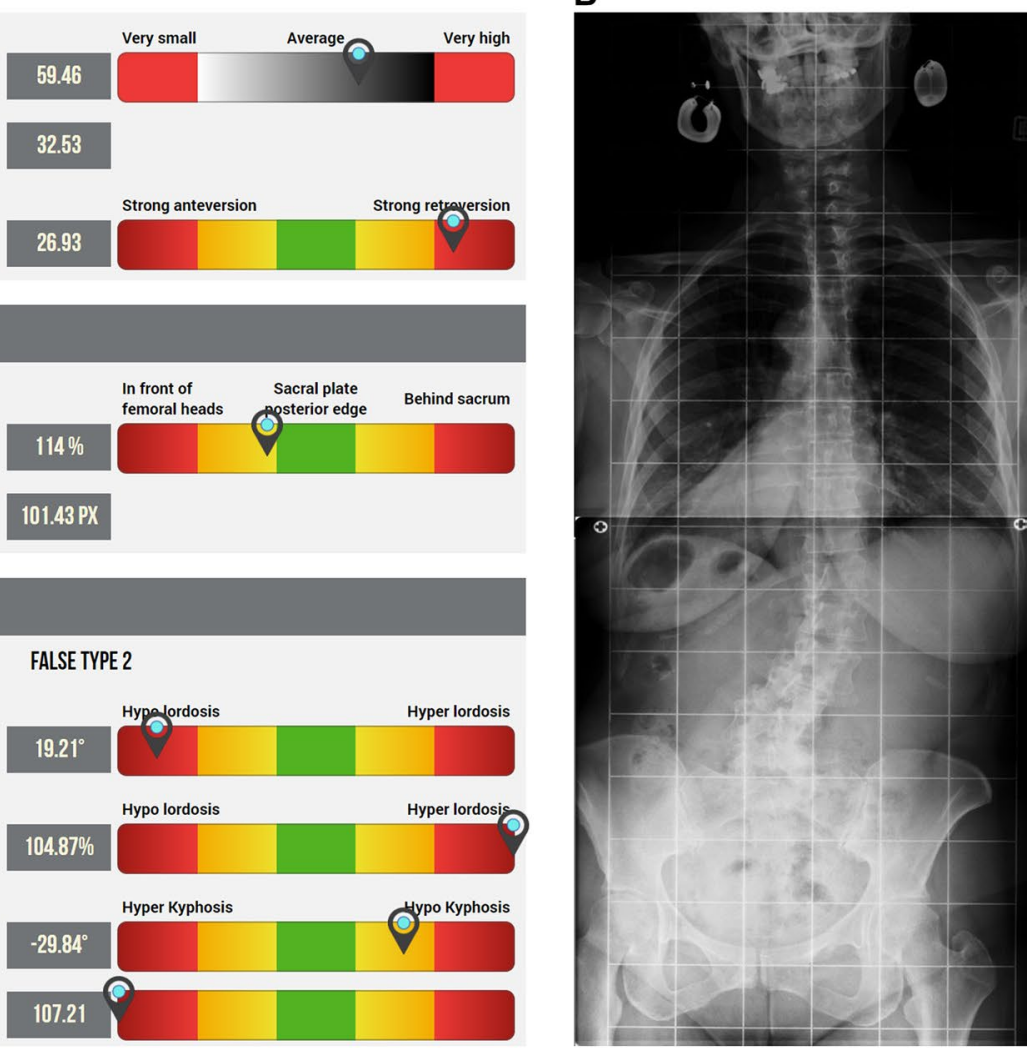

D

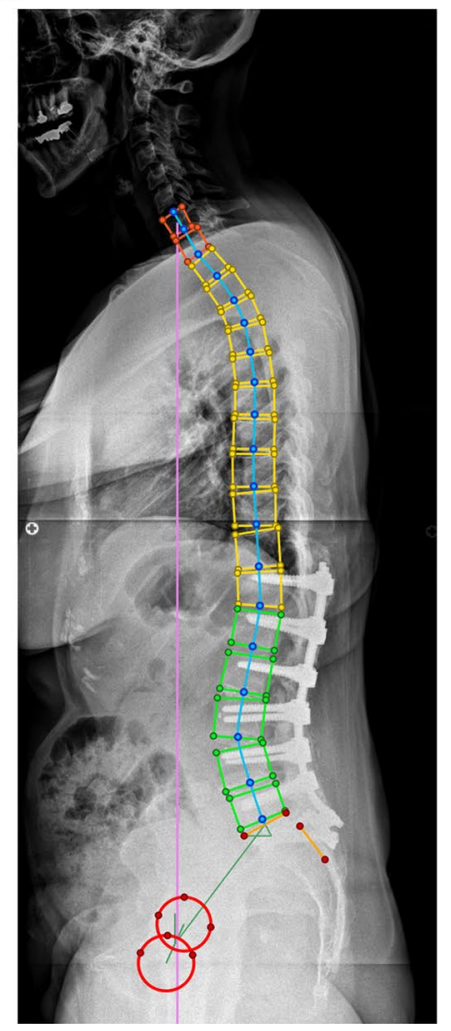


Table 2 Demographic and parameters comparison between patients with complications and patients without complications

\begin{tabular}{llll}
\hline & $\begin{array}{l}\text { Patients without } \\
\text { complication }\end{array}$ & $\begin{array}{l}\text { Patients with } \\
\text { complications }\end{array}$ & $p^{*}$ \\
\hline Percentage & 69.6 & 30.4 & \\
Gender & $78.7 \%$ & $77 \%$ & NS \\
BMI & 25 & 26 & NS \\
Age & 57.3 years & 60.3 years & $p=0.06$ \\
Pelvic incidence & $51.5^{\circ}$ & $55.2^{\circ}$ & $p=0.06$ \\
Preoperative & & & \\
Pelvic tilt & $22.1^{\circ}$ & $26.2^{\circ}$ & $\boldsymbol{p}=\mathbf{0 . 0 0 3}$ \\
Sacral slope & $28.9^{\circ}$ & $29.7^{\circ}$ & NS \\
Spinal lordosis (SL) & $46.5^{\circ}$ & $42.8^{\circ}$ & NS \\
Spinal kyphosis (SK) & $51.8^{\circ}$ & $47^{\circ}$ & NS \\
Barrey ratio & $86 \%$ & $88 \%$ & NS \\
Global tilt & $63^{\circ}$ & $64^{\circ}$ & NS \\
Postoperative & & & \\
Pelvic tilt & $19.7^{\circ}$ & $22.4^{\circ}$ & $\boldsymbol{p}=\mathbf{0 . 0 1 5}$ \\
Sacral slope & $31.5^{\circ}$ & $31.2^{\circ}$ & NS \\
Spinal lordosis (SL) & $49.7^{\circ}$ & $51.3^{\circ}$ & NS \\
Spinal kyphosis (SK) & $50.8^{\circ}$ & $50.7^{\circ}$ & NS \\
Barrey ratio & $80 \%$ & $120 \%$ & $\boldsymbol{p}=\mathbf{0 . 0 1}$ \\
Global tilt & $59.5^{\circ}$ & $59.3^{\circ}$ & NS \\
\hline BMIbody & & \\
\hline
\end{tabular}

$B M I$ body mass index, $N S$ nonsignificant

${ }^{*}$ Values in bold are statistically significant

may be divided in two angles: the lower angle that is equal to SS and the upper angle that is equal to the lower angle of kyphosis [19]. Restoration of a normal shape is based on preoperative PI recognition.

In the case of low PI, the only options for restoration are type 1 or type 2 shapes. Due to the low PI, possibility of pelvic retroversion is low (low PT) and balance compensation by this way is limited. Roughly, a preoperative flat back (type 2) has to stay flat. On the other hand, a pre-existing thoracic kyphosis is better to be reduced in type 1, extending the kyphosis in thoraco-lumbar area as was shown by Scemama et al. [20]. In any case, increasing lordosis in length and angle and thus turning the spinal shape into an anteverted type 3 is a bad option and results in high rates of PJK [20,21].

In the case of high PI $\left(>50^{\circ}\right)$, sagittal imbalance is always compensated by pelvic retroversion; sometimes, spinal extension compensation may be associated with a decreased thoracic kyphosis. Using SL segmentation, correction of SS to reduce PT is based on the lower angle correction and if using osteotomy the osteotomy site has to be as distal as possible [22]. If the reduction focuses on the upper arc without correcting the lower one, the SS correction will be very poor and the increasing upper arc of lordosis induces an increasing lower arc of kyphosis leading to mechanical complications, especially PJK. The second trap is the hypokyphosis compensation. If the lordosis is restored, the need for thoracic compensation disappears turning the thoracic area in kyphosis that is another cause of PJK (this time it is a rebalancing PJK).

In summary, the PI value of the initial shape is poorly affected by the degeneration with small balance compensation and thus maintaining the shape is quite easy and always a good option. Type 1 remains problematic for the majority of spine surgeons because reducing the thoracolumbar kyphosis is a common belief that generally leads to complications by inducing an anteverted type 3 that is always a bad option [20]. In the cases where there are compensatory mechanisms, the initial shape has therefore changed. Restoration of the initial shape according to PI with high PT is more challenging as has been shown that the false type 2 had the highest rate of mechanical complications. Therefore, in older patients a moderate correction may be a better option rather than ideal balance that cannot be supported in elderlies. When PI is over $70^{\circ}$, a more distal correction is a better option and a L5 PSO has to be considered to counter-act the excessive SS [23].

This study found that the most important factor in limiting mechanical complications is no other than the restoration of the sagittal shape of the spine to its original profile according to the Roussouly classification. Nonetheless, surgeons should be aware of the technical difficulty of this task as we found that most of the patients in whom the algorithm could not be abided by, had a higher preoperative PT.

This study has several limitations. Functional scores (Oswestry, SRS-30, SF12...) were not evaluated neither correlated with the morphotypes described by Roussouly. Moreover, this is a cross-sectional study with data collection unable to identify trends of degenerative evolution of the patients' spines. Finally, this is a retrospective study with some unexploitable data and some missing values (such as bone density to study the effect of osteoporosis). In a further study, a complete algorithm to restore the pathological shape to normal shape will have to be described.

\section{Conclusion}

In the recent literature, there are no clear guidelines for surgical ASD correction objectives. The proposed algorithm by Roussouly could serve as a guideline for the treatment of ASD since it focuses on the entire spinal shape to the Roussouly classification according the patients PI. Ignoring this algorithm is associated with a threefold risk of increasing mechanical complications. 


\section{Compliance with ethical standards}

Conflict of interest The authors declare that they have no conflict of interest.

Open Access This article is licensed under a Creative Commons Attribution-NonCommercial 4.0 International License, which permits any non-commercial use, sharing, adaptation, distribution and reproduction in any medium or format, as long as you give appropriate credit to the original author(s) and the source, provide a link to the Creative Commons licence, and indicate if changes were made. The images or other third party material in this article are included in the article's Creative Commons licence, unless indicated otherwise in a credit line to the material. If material is not included in the article's Creative Commons licence and your intended use is not permitted by statutory regulation or exceeds the permitted use, you will need to obtain permission directly from the copyright holder. To view a copy of this licence, visit https://creativecommons.org/licenses/by/4.0/.

\section{References}

1. Jimbo S, Kobayashi T, Aono K et al (2012) Epidemiology of degenerative lumbar scoliosis: a community-based cohort study. Spine (Phila Pa 1976) 37:1763-1770. https://doi.org/10.1097/ BRS.0b013e3182575eaa

2. Glassman SD, Bridwell K, Dimar JR et al (2005) The impact of positive sagittal balance in adult spinal deformity. Spine (Phila Pa 1976) 30:2024-2029. https://doi.org/10.1097/01.brs.00001 79086.30449.96

3. Wolff S, Kheirredine W, Riouallon G (2012) Surgical dural tears: prevalence and updated management protocol based on 1359 lumbar vertebra interventions. Orthop Traumatol Surg Res 98:879-886. https://doi.org/10.1016/j.otsr.2012.06.016

4. Riouallon G, Bouyer B, Wolff S (2016) Risk of revision surgery for adult idiopathic scoliosis: a survival analysis of 517 cases over 25 years. Eur Spine J. https://doi.org/10.1007/s0058 6-016-4505-5

5. Lowe TG, Kasten MD (1994) An analysis of sagittal curves and balance after Cotrel-Dubousset instrumentation for kyphosis secondary to Scheuermann's disease. A review of 32 patients. Spine (Phila Pa 1976) 19:1680-1685

6. Lee GA, Betz RR, Clements DH, Huss GK (1999) Proximal kyphosis after posterior spinal fusion in patients with idiopathic scoliosis. Spine (Phila Pa 1976) 24:795-799

7. Yagi M, Rahm M, Gaines R et al (2014) Characterization and surgical outcomes of proximal junctional failure in surgically treated patients with adult spinal deformity. Spine (Phila $\mathrm{Pa}$ 1976) 39:E607-E614. https://doi.org/10.1097/BRS.0000000000 000266

8. Park Y-S, Hyun S-J, Park J-H et al (2017) Radiographic and clinical results of freehand $\mathrm{s} 2$ alar-iliac screw placement for spinopelvic fixation: an analysis of 45 consecutive screws. Clin spine Surg. https://doi.org/10.1097/BSD.0000000000000520

9. Roussouly P, Gollogly S, Berthonnaud E, Dimnet J (2005) Classification of the normal variation in the sagittal alignment of the human lumbar spine and pelvis in the standing position.
Spine (Phila Pa 1976) 30:346-353. https://doi.org/10.1097/01. brs.0000152379.54463.65

10. Laouissat F, Sebaaly A, Gehrchen M, Roussouly P (2017) Classification of normal sagittal spine alignment: refounding the Roussouly classification. Eur Spine J. https://doi.org/10.1007/ s00586-017-5111-x

11. Sebaaly A, Grobost P, Mallam L, Roussouly P (2017) Description of the sagittal alignment of the degenerative human spine. Eur Spine J. https://doi.org/10.1007/s00586-017-5404-0

12. Lafage R, Schwab F, Challier V et al (2016) Defining spino-pelvic alignment thresholds: should operative goals in adult spinal deformity surgery account for age? Spine (Phila Pa 1976) 41:6268. https://doi.org/10.1097/BRS.0000000000001171

13. Sebaaly A, Riouallon G, Obeid I et al (2018) Proximal junctional kyphosis in adult scoliosis: comparison of four radiological predictor models. Eur Spine J 27:613-621. https://doi.org/10.1007/ s00586-017-5172-x

14. Maillot C, Ferrero E, Fort D et al (2015) Reproducibility and repeatability of a new computerized software for sagittal spinopelvic and scoliosis curvature radiologic measurements: Keops? Eur Spine J. https://doi.org/10.1007/s00586-015-3817-1

15. Barrey C, Jund J, Noseda O, Roussouly P (2007) Sagittal balance of the pelvis-spine complex and lumbar degenerative diseases. A comparative study about 85 cases. Eur Spine J 16:1459-1467. https://doi.org/10.1007/s00586-006-0294-6

16. Glattes RC, Bridwell KH, Lenke LG et al (2005) Proximal junctional kyphosis in adult spinal deformity following long instrumented posterior spinal fusion: incidence, outcomes, and risk factor analysis. Spine (Phila Pa 1976) 30:1643-1649. https://doi. org/10.1097/01.brs.0000169451.76359.49

17. Sebaaly A, Sylvestre C, El Quehtani Y et al (2018) Incidence and risk factors for proximal junctional kyphosis: results of a multicentric study of adult scoliosis. Clin Spine Surg 31:E178-E183. https://doi.org/10.1097/BSD.0000000000000630

18. Berthonnaud E, Dimnet J, Roussouly P, Labelle H (2005) Analysis of the sagittal balance of the spine and pelvis using shape and orientation parameters. J Spinal Disord Tech 18:40-47. https:// doi.org/10.1097/01.bsd.0000117542.88865.77

19. Berthonnaud E, Labelle H, Roussouly P et al (2005) A variability study of computerized sagittal spinopelvic radiologic measurements of trunk balance. J Spinal Disord Tech 18:66-71

20. Scemama C, Laouissat F, Abelin-Genevois K, Roussouly P (2017) Surgical treatment of thoraco-lumbar kyphosis (TLK) associated with low pelvic incidence. Eur Spine J. https://doi.org/10.1007/ s00586-017-4984-z

21. Ferrero E, Vira S, Ames CP et al (2016) Analysis of an unexplored group of sagittal deformity patients: low pelvic tilt despite positive sagittal malalignment. Eur Spine J 25:3568-3576. https://doi. org/10.1007/s00586-015-4048-1

22. Sebaaly A, Rizkallah M, Kreichati G, Kharrat K (2016) Influence of the level of pedicle subtraction osteotomy on pelvic tilt change in adult spinal deformity. In: Global Spine Congress, $p 17$

23. Alzakri A, Boissière L, Cawley DT et al (2017) L5 pedicle subtraction osteotomy: indication, surgical technique and specificities. Eur Spine J. https://doi.org/10.1007/s00586-017-5403-1

Publisher's Note Springer Nature remains neutral with regard to jurisdictional claims in published maps and institutional affiliations. 


\section{Affiliations}

\section{Amer Sebaaly $1,2,3$ - Martin Gehrchen ${ }^{4}$ Clément Silvestre ${ }^{1} \cdot$ Khalil Kharrat $^{2,3} \cdot$ Tanvir Johanning Bari $^{4}$.} Gabi Kreichati $^{2,3} \cdot$ Maroun Rizkallah $^{2,3} \cdot$ Pierre Roussouly $^{1}$

$\triangle$ Amer Sebaaly

amersebaaly@hotmail.com

1 Department of Orthopedic Surgery, Clinique médicochirurgicale des Massues, Lyon, France

2 Department of Orthopedic Surgery, Hotel Dieu de France Hospital, Alfred Naccache Boulevard, Beirut, Lebanon
3 Faculty of Medicine, Saint Joseph University, Beirut, Lebanon

4 Department of Orthopaedic Surgery, Rigshospitalet, University Hospital of Copenhagen, 9 Blegdamsvej, 200 Copenhagen, Denmark 